\title{
A Comparative Study on Surface Treatments in the Immobilization Improvement of Hexahistidine-tagged Protein on the Indium Tin Oxide Surface
}

\author{
Ismail MB ${ }^{1 *}$, Pastor $\mathrm{NC}^{2}$, Soler EP${ }^{2}$, Soltani $\mathrm{A}^{1}$ and Othmane $\mathrm{A}^{1}$
}

${ }^{1}$ Interfaces and Advanced Materials Laboratory, Faculty of Medicine, University of Monastir, 5019 Monastir, Tunisia

${ }^{2}$ Institut de Ciencia de Materials de Barcelona, CSIC, Campus UAB, 08193 Bellaterra, Barcelona, Spain

\begin{abstract}
Biosensors are becoming increasingly important in various sectors. However, choosing transducer type and surface treatment still faces severe limitations. Indium-tin oxide is widely used in electrochemical sensing, though surface cleaning and functionalization are not always straightforward and often poorly controlled. Here, we have covalently immobilized a hexahistidine-tagged model protein on three different treated ITO surfaces using a $\mathrm{Ni}^{2+}$ chelator moiety. The study shows that compared to two other treatments $\left(\mathrm{H}_{2} \mathrm{O} / \mathrm{H}_{2} \mathrm{O}_{2} / \mathrm{NH}_{4} \mathrm{OH}\right.$ and $\mathrm{KOH}$ treatments), the ITO Piranha treatment gives satisfactory results in term of yields of EC12 protein immobilized on the surface. The study in detail of treatments effect was realized by applying a combination of local and global techniques such X-ray photoelectron spectroscopy (XPS), atomic force microscopy (AFM), Attenuated total reflectance Fourier transform infrared spectroscopy (FTIR-ATR), contact angle measurements, and electrochemical impedance spectroscopy (EIS). The biofunctionalization allowed proteins to move freely around their anchoring bond. As the polyhistidine tags are widely used in protein engineering, such substrates offer a large panel of applications. This covalent and oriented immobilization process of recombinant proteins applied to ITO could provide transparent electroactive surfaces of high quality for electrochemical detection of soluble compounds, as well as cells.
\end{abstract}

Keywords: Indium tin oxide; Piranhatreatment;Biofunctionalization; AFM; XPS; Histidine-tagged proteins; Electrochemistry

\section{Introduction}

Because of its remarkable feature of associating light transparency and electrical conductivity, ITO has been used, despite its cost, as a transparent electrode in many technological applications such as optoelectronic devices [1-4] and solar cells [5,6]. Device efficiency strongly depends on ITO surface treatment and much effort has been spent on this critical point [3,7-10]. Despite numerous attempts to optimize ITO chemical and physical properties, especially surface roughness, there is no general agreement on the ideal procedure to produce the best ITO surface for sensors. Clearly, the quality of ITO thin films strongly depends on the deposition technique $[10,13]$, which further influences the efficiency of post-treatments.

A number of new applications concern the development of biological sensing technologies for environmental, food and medical applications [14-16], with many challenges related to the proper functionalization of ITO surfaces. The first step is to perform an ITO pretreatment that eliminates impurities, controls surface roughness, and creates functional groups on the surface. Both dry and wet cleaning processes have been investigated such as argon ion bombardment, hydroxylation in ultra-high vacuum [9], UV-ozone irradiation [17], oxygen plasma treatment [18] and acidic or alkaline treatments [7]. Afterwards the surface is often modified through grafting of a molecular spacer between ITO and the active layer. This provides versatility in the surface chemistry and allows proper anchoring of proteins that could be denatured by physisorption on ITO surface. Many studies have used $\gamma$-glycidoxypropyl-trimethoxy silane (GPTMS) as a versatile epoxysilane coupling agent with a reactive epoxide on one end and a hydrolysable inorganic methoxysilyl group on the other end. The dual nature of its reactivity allows the GPTMS molecule to bind covalently to inorganic materials (e.g. glass, metals, etc.) through the methoxysilyl group and to organic molecules through the epoxide termination, thus functioning as an adhesion promoter, a crosslinking agent and a surface modifier. GPTMS has been claimed to form dense and complete self-assembled monolayers (SAMs) [19] on various substrates including stainless steel [20], aluminum alloy [21], electrochemicallyoxidized glassy carbon electrodes p [22], silicon [23,24] and ITO [14]. Furthermore, it has been used to crosslink different biomolecules such as proteins [25-27], and DNA [28].

In this work, we used nitrilotriacetic acid (NTA), a widely used metal chelator complex, to provide efficient oriented binding of hexahistidine-tagged proteins. NTA was attached to the ITO surface through a GPTMS linkage. The chelation of the hexahistidine sequence to the $\mathrm{Ni}^{2+}$-NTA complex is reversible, depending on ionic strength, $\mathrm{pH}$ and media conditions. In order to ensure a stable functionalization, we performed an amide linkage between the amino groups of the histidine lateral chains and the carboxylated groups of the NTA moiety [25,29]. We adapted the protocol described for coverslips by Chevalier et al. [25]. As in (Chevalier et al. [25] the prototypic protein was a bimodular recombinant fragment of E-cadherin (E/EC12). Cadherins, expressed in various tissues, are a superfamily of adhesive receptors involved in $\mathrm{Ca}^{2+}$-dependent cell-cell interactions [30]. The epithelial cadherin (E-cadherin) is a transmembrane glycoprotein whose extracellular segment contains five modules involved in homophilic interactions

*Corresponding authors: Manel Ben Ismail, Molecular Biology and Biochemistry Research Center for Nanomedicine (Cibbim-Nanomedicine), Vall d'Hebron Institu de Recerca (VHIR). Passeig de la Vall d'Hebron, 11912908035 Barcelona, Spain, Tel: 34935801853; E-mail: manel.ben_ismail@vhir.org

Received April 11, 2016; Accepted April 24, 2016; Published April 30, 2016

Citation: Ismail MB, Pastor NC, Soler EP, Soltani A, Othmane A (2016) A Comparative Study on Surface Treatments in the Immobilization Improvement of Hexahistidine-tagged Protein on the Indium Tin Oxide Surface. J Nanomed Nanotechnol 7: 372. doi:10.4172/2157-7439.1000372

Copyright: @ 2016 Ismail MB, et al. This is an open-access article distributed under the terms of the Creative Commons Attribution License, which permits unrestricted use, distribution, and reproduction in any medium, provided the original author and source are credited. 
Citation: Ismail MB, Pastor NC, Soler EP, Soltani A, Othmane A (2016) A Comparative Study on Surface Treatments in the Immobilization Improvement of Hexahistidine-tagged Protein on the Indium Tin Oxide Surface. J Nanomed Nanotechnol 7: 372. doi:10.4172/2157-7439.1000372

leading to cell adhesion (binding to identical molecules on adjacent cells) [31-34]. Cadherin E/EC12 fragments have been used to create very efficient biomimetic surfaces for studying cell signaling $[35,36]$.

In order to improve the quality of ITO and increase E/EC12 fragments grafting on the surface, a combination of different cleaning procedures was used. The substrates were characterized to follow the efficiency of the post-treatment electrodes using several techniques: X-ray photoelectron spectroscopy (XPS), atomic force microscopy (AFM), contact angle measurements, Attenuated total reflectance Fourier transform infrared spectroscopy (FTIR-ATR) and electrochemical impedance spectroscopy (EIS).

\section{Experimental}

\section{Materials}

Acetone, sulfuric acid (ACS reagent, 95-98\%), hydrogen peroxide (30\%), N-(5-amino-1-carboxypentyl) iminodiacetic acid ( $\geq 97 \%)$ (NTA-NH ${ }_{2}$ ), sodium carbonate $(\geq 99 \%)$ and sodium bicarbonate (99.7\%), nickel II chloride hexahydrate, Hepes ( $\geq 99.5 \%), \mathrm{N}-(3-$ dimethylaminopropyl)-N'-ethylcarbodiimide hydrochloride crystalline (EDC), N-hydroxysuccinimide ( $\geq 97 \%$ ) (NHS), imidazole (ACS reagent, $\geq 99 \%$ ), ethylenediaminetetraacetic (EDTA, $\geq 99 \%$ ), and ammonium hydroxide (28-33\%) were purchased from Sigma-Aldrich, France. Dry toluene (99.8\%) and an epoxysilane compound, (3-glycidyloxypropyl) trimethoxysilane ( $\geq 98 \%$ ) (GPTMS) (Sigma-Aldrich, France) were employed for the monolayer film formation. For electrochemical experiments, potassium ferrocyanide and potassium ferricyanide were purchased from Sigma-Aldrich, France. ITO coated glass, which has a surface resistance $\leq 200 \Omega$, was cut into small pieces of predefined geometric area $(1 \mathrm{~cm} \times 1.5 \mathrm{~cm})$ to be used as working electrodes. All the chemicals were used as received. Ultrapure water obtained from a water purification system MILLI-Q A10 was used to prepare all the aqueous solutions.

\section{Cleaning and pretreatment of ITO substrates}

First, a general cleaning process was used for all ITO substrates. Samples were soaked $15 \mathrm{~min}$ in ultrasonic acetone bath, cleaned using the RCA process, which involves heating the ITO in a 20:4:1 solution of $\mathrm{H}_{2} \mathrm{O}: \mathrm{H}_{2} \mathrm{O}_{2}: \mathrm{NH}_{4} \mathrm{OH}$ for $20 \mathrm{~min}$ at $60^{\circ} \mathrm{C}$, rinsed thoroughly with water, and again immersed into acetone for $10 \mathrm{~min}$ and dried with a stream of nitrogen gas. These samples were named "bare ITO". Second, ITO samples, named "KOH-treated ITO", went through a chemical etching process in saturated $\mathrm{KOH} /$ isopropanol solution for $24 \mathrm{~h}$ at room temperature (Bazin et al., 2012; Liu et al., 2004). After 15 min of isopropanol bath, the etched ITO glass samples went through three cleaning steps: $15 \mathrm{~min}$ in ultrasonic acetone bath, RCA treatment, rinsing in water, then again immersed into acetone bath for $10 \mathrm{~min}$ and finally dried with a stream of nitrogen gas. Final ITO substrates, noted "Piranha-treated ITO", were prepared as described before, and then soaked in piranha solution $\left(1: 4 / \mathrm{H}_{2} \mathrm{O}_{2}: \mathrm{H}_{2} \mathrm{SO}_{4}\right)$ for $1 \mathrm{~min}$, thoroughly washed with deionized water, and then dried under $\mathrm{N}_{2}$ gas.

\section{GPTMS functionalization of ITO substrates}

We used the same protocol as in our previous work on glass [25], with slight modification for the final treatment. ITO substrates were immersed in a dry toluene solution of GPTMS $(2 \%)$ overnight at $60^{\circ} \mathrm{C}$. Afterwards the substrate was thoroughly rinsed with toluene and finally, substrates were immersed again in toluene and heated for 10 min at $100^{\circ} \mathrm{C}$. All samples were then dried under $\mathrm{N}_{2}$ gas.

\section{Biofunctionalization with polyhistidine-tagged proteins}

The E/EC12 recombinant proteins were expressed and purified according to Perret et al. [33]. To immobilize these fragments on silanized ITO, we adapted the protocol described in [25]. First, ITOGPTMS substrates, after rinsing with $10 \mathrm{mM}$ carbonate buffer $\mathrm{pH} 10.8$, were incubated overnight with $25 \mathrm{mM}$ NTA- $\mathrm{NH}_{2}$ in carbonate buffer $(\mathrm{pH} 10.8)$, washed and dried. Then, the substrates were incubated with a $100 \mathrm{mM}$ aqueous solution of $\mathrm{NiCl}_{2}$ to form the complexation environment for the hexahistidine motif. The samples were incubated in the presence of 6His-tagged EC12 fragments $(0.1 \mathrm{mg} / \mathrm{mL})$ for $1 \mathrm{~h}$ at room temperature (RT), and then extensively washed with $20 \mathrm{mM}$ Hepes $/ 150 \mathrm{mM} \mathrm{NaCl} \mathrm{pH}=7.0$. The covalent cross-linking between carboxylic groups of the NTA moiety and amino groups of the protein fragments was performed by incubating the supports for $45 \mathrm{~min}$ at RT in $50 \mathrm{mM}$ EDC, $75 \mathrm{mM}$ NHS in $20 \mathrm{mM}$ Hepes (pH 7.0) solution. The non-covalently linked proteins were removed by $1 \mathrm{M}$ imidazole, 10 $\mathrm{mM}$ EDTA in Hepes/ $\mathrm{NaCl}$ buffer at $\mathrm{pH}=7.0$. Finally, all samples were extensively rinsed with $20 \mathrm{mM}$ Hepes $150 \mathrm{mM} \mathrm{NaCl}$ buffer $\mathrm{pH}=7.0$. The complete protocol is sketched Figure 1.

Optical properties of treated ITO surfaces were monitored by FTIR-ATR measurements carried out on a ZnSe disk by use of a Perkin-Elmer FTIR spectrophotometer in a wave number range of 4000 to $650 \mathrm{~cm}^{-1}$. The data extraction was done using the Spectrum v5.3.1 software. Electronic properties of these surfaces were controlled by conductivity measurements using conductive sensing AFM for current sensing measurements, which also provides an idea about surface topography. The apparatus (Agilent $5500 \mathrm{AFM}$ ) is equipped with a ResiScope Module, a silicon cantilever and a tip coated with polycrystalline diamond. AFM images ( $5 \mu \mathrm{m} \times 5 \mu \mathrm{m}$ area) were collected simultaneously and analyzed using Mountain Map 6 software (Digital Surf).

Bare and modified ITO electrodes were characterized by their contact angles with water using the static sessile drop method. A deionized water droplet $(3 \mu \mathrm{l})$ was made on the tip of a syringe and placed on the ITO surface by manually moving the substrate vertically until contact was made. An image sequence was taken through a CCD

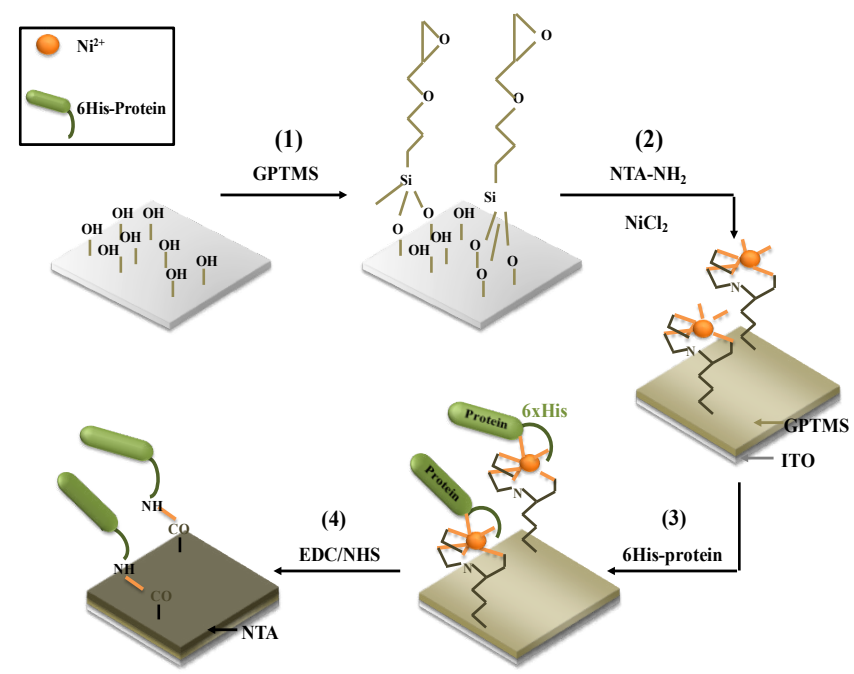

Figure 1: Schematic illustration of the various steps leading to oriented and covalent ITO biofunctionalization: (1) epoxysilane layer anchoring on $\mathrm{KOH}$ treated ITO surfaces, (2) NTA-Nii ${ }^{2+}$ grafting, (3) oriented binding through chelation of hexahistidine-tagged recombinant cadherin fragments (E/EC12), (4) covalent E/EC12 binding. 
Citation: Ismail MB, Pastor NC, Soler EP, Soltani A, Othmane A (2016) A Comparative Study on Surface Treatments in the Immobilization Improvement of Hexahistidine-tagged Protein on the Indium Tin Oxide Surface. J Nanomed Nanotechnol 7: 372. doi:10.4172/2157-7439.1000372

Page 3 of 6

camera of a goniometer (GBX Scientific Instruments, Romans France) connected to a PC computer and interfaced to image capture software (Windrop). The values reported were the average of contact angles measured at three different locations of three samples.

XPS was carried out on a Thermo-VG Scientific ESCALAB $220 \mathrm{iXL}$ spectrometer, equipped with a monochromatic Al Ka X-ray source $(1486.6 \mathrm{eV})$. The spectra were collected with $20 \mathrm{eV}$ constant pass energy. The sample was perpendicular to the detector axis. The collected XPS data were fitted with a combination of Gaussian-Lorentzian line shapes, after correction for the Shirley background, by using the Avantage software from Thermofisher Scientific. Curve fitting procedure was performed according to criteria described by Briggs for surface analysis of polymers (Briggs, 1998).

The electrochemical behavior was studied by impedance spectroscopy (EIS). Measurements were carried out using a Voltalab 40 PGZ 301 analyzer in a Faraday cage at ambient temperature using a three-electrode electrochemical cell with a saturated calomel $(\mathrm{Hg} /$ $\mathrm{Hg}_{2} \mathrm{Cl}_{2} / \mathrm{KCl}$ ) electrode as a reference electrode and a platinum counter electrode. The experiments were performed in phosphate buffer solution (PBS, pH 7.4) containing $5 \mathrm{mM} \mathrm{K}_{3} \mathrm{Fe}(\mathrm{CN})_{6} / \mathrm{K}_{4} \mathrm{Fe}(\mathrm{CN})_{6}(1: 1)$ redox couple. Real and imaginary parts of impedance were measured in a frequency range between $10 \mathrm{mHz}$ and $100 \mathrm{kHz}$ using sinusoidal voltage of $5.0 \mathrm{mV}$ amplitude. Zview modeling software was used to analyze data.

\section{Results and Discussion}

The immobilized protein amount on the modified surfaces is related to the quality of GPTMS SAMs, which is known to depend strongly on the surface state of the supporting material. The roughness state and the coverage of hydroxide at the ITO surface are important points that should be considered. Various surface etching and bioactivation approaches have been reported [37-39]. For this reason, we decided to treat ITO with $\mathrm{KOH}$ as it was already shown to decrease surface roughness [39]. And then, we treated ITO with piranha solution as it was demonstrated to increase the hydroxide species concentration on ITO [37].

\section{Pretreatment and cleaning of ITO}

ITO substrate has been chosen in this study especially for its optical transparence, so the first point we studied was the pretreatments effect on the ITO transmission by FTIR-ATR (Figure 2). The IR spectra of different ITO substrates showed that with different treatments we have an almost stable transmission $(\approx 100 \%)$.

The current sensing atomic force microscopy (CSAFM) was used to examine simultaneously the conductivity and topology of the different pretreated ITO surfaces (Figure 3). The non-homogeneity of surface state can arise because of some surfaces imperfections (dust particles, scratches, pits, polishing spots or granularity in layers deposited on the surface). The electrical property was affected by the different treatments. It was obvious that $\mathrm{KOH}$-treatment led to an increase of current conductivity (Figure 3b). We may suggest that the surface flattening by $\mathrm{KOH}$ treatment may lead to an increased AFM tip-ITO surface contact area that could be responsible for the conductance increase. However, the piranha-treatment showed a slight decrease of conductivity. This electric conductivity deviation could be explained by the variation of the metal species (In, Sn) on the ITO surfaces [38]. The piranha solution, used to remove the ITO coating thin films by [40], was always avoided as a treatment for ITO because of its probable aggressive reaction that could dissolve organic and inorganic materials. Except that Armstrong et al., [38] showed that the highest concentration of hydroxide species on the ITO surface was obtained after piranha solution treatment which is an important point for further functionalization.

The topography also changed after both treatments. First, the "bare ITO" showed a moderately flat substrate with some dark areas referring to a probable difference of ITO heights (a peak-to-peak height variation of about $5 \mathrm{~nm}$ ). However, after $\mathrm{KOH}$ and Piranha treatments, the substrate showed better homogeneity with decreased roughness, and lower pinhole density that remains smooth at the sub-nanometer scale (RMS $<0.4 \mathrm{~nm}$ ) as estimated by [3]. The chemical polishing effect of $\mathrm{KOH}$ seems to depend on the ITO quality since it was observed by Liu et al. [3] but not by Gardonio et al. [7].

In order to verify these results, we investigate the hydrophilic/ hydrophobic nature of the substrate by measuring the contact angle (Figure 4). Bare ITO (Figure 4a), moderately hydrophobic $\left(54.90^{\circ} \pm\right.$ $0.7)$, showed a slightly decrease of contact angle $\left(45.29^{\circ} \pm 0.5\right)$ upon $\mathrm{KOH}$-pretreatment (Figure $4 \mathrm{~b}$ ). But after piranha-treatment (Figure 4c), contact angle decreased drastically $(15.38 \pm 0.5)$ showing a highly hydrophilic surface. We could suggest that the piranha-treatment leads to an increase in hydroxyl group density, which is in accordance with (Armstrong et al., 2003), as well as a decrease in roughness despite the decrease of conductivity.

To deepen the study of treatment impacts on ITO, XPS, which is a priori the perfect tool to characterize the surface chemistry was used. The surface elemental composition (C, O, In, Sn, Si, K and N) has been obtained and reported in Table 1 . The absence of any trace of potassium on both $\mathrm{KOH}$ and Piranha-treated ITO means that alkaline treatment did not modify the overall surface composition on the depth investigated by XPS $(<10 \mathrm{~nm})$. Moreover, Piranha-treatment, showing the same $(\mathrm{Sn} / \mathrm{In})$ ratio for all the treated surfaces $(\approx 0.08)$, did not

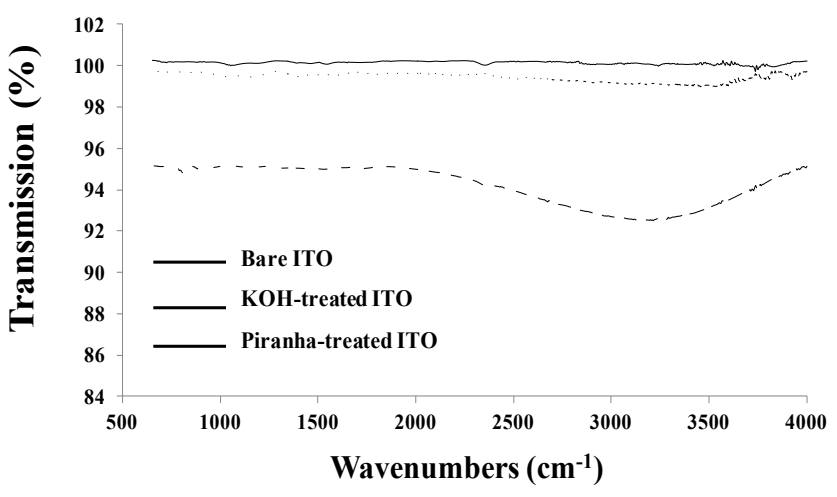

Figure 2: ATR-FTIR spectra of different ITO treatments.
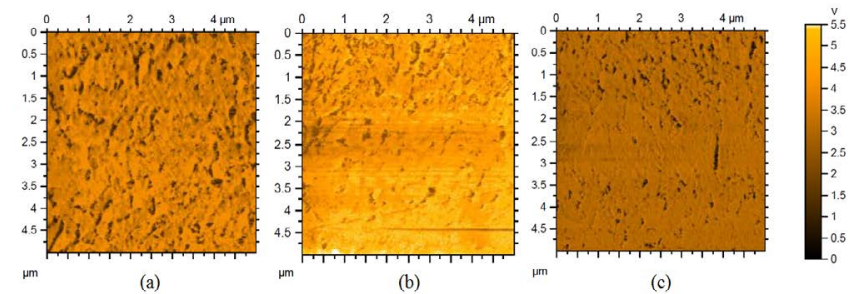

Figure 3: Current sensing atomic force microscopy images (CSAFM) of different bare ITO surfaces: (a) Native ITO, (b) ITO with KOH treatment, (c) ITO with Piranha treatment. 


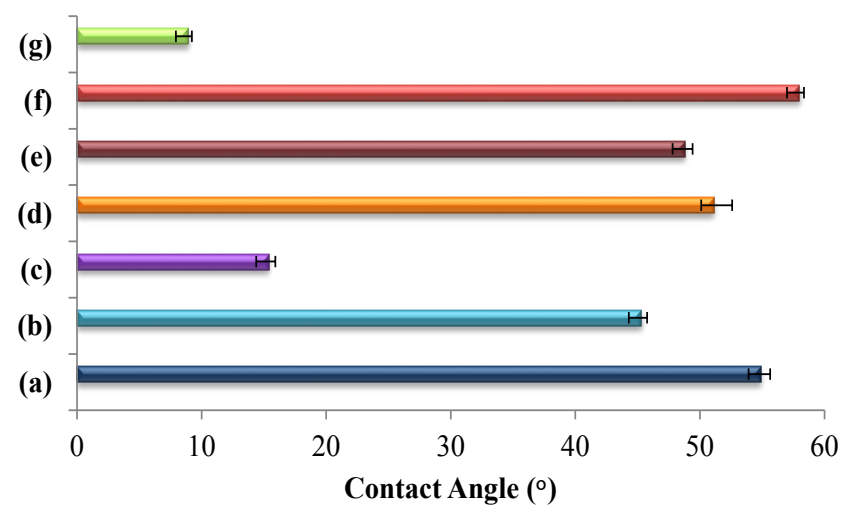

Figure 4: Surface wettability measurement of the modified ITO shows the water static contact angles of bare ITO (a), KOH-treated ITO (b), Piranha-treated ITO (c), bare ITO/GPTMS (d), KOH-treated ITO/GPTMS (e) Piranha-treated ITO/ GPTMS (f), Piranha-treated ITO/NTA-NH ${ }_{2}(\mathrm{~g})$.

\begin{tabular}{|c|c|c|c|c|c|c|c|c|}
\hline & & \multicolumn{7}{|c|}{ Element (\%) } \\
\hline Substrate & Treatment & C & 0 & In & Sn & $\mathbf{S i}$ & $\mathbf{K}$ & $\mathbf{N}$ \\
\hline ITO & \multirow{2}{*}{ Bare } & 25.03 & 41.62 & 30.04 & 2.55 & - & - & 0.76 \\
\hline ITO/GPTMS & & 55.81 & 28.34 & 3.8 & 0.34 & 11.2 & - & 0.51 \\
\hline ITO & \multirow{2}{*}{$\mathrm{KOH}$-treated } & 27.74 & 40.39 & 29.39 & 2.48 & - & - & - \\
\hline ITO/GPTMS & & 42.65 & 36.76 & 12.08 & 1.06 & 6.93 & - & 0.52 \\
\hline ITO & \multirow{2}{*}{$\begin{array}{l}\text { Piranha- } \\
\text { treated }\end{array}$} & 34.52 & 41.42 & 21.93 & 2.13 & - & - & - \\
\hline ITO/GPTMS & & 49.71 & 34.25 & 1.28 & 0.12 & 14.64 & - & - \\
\hline
\end{tabular}

Table 1: XPS surface composition of bare, $\mathrm{KOH}$ and Piranha treated ITO, and after GPTMS deposition (Atomic \%)

damage the ITO surfaces as mentioned by [40]. However, similar low carbonaceous contamination layers were observed on both bare and $\mathrm{KOH}$-treated ITO, contrary to Piranha-treated ITO which is slightly higher. These results are consistent with the CS-AFM results. The contaminating layer prevents the creation of an ohmic contact between the ITO surface and the conducting cantilever as demonstrated by [41].

\section{GPTMS deposition on ITO}

The GPTMS was used as a coupling agent. The formation of a homogeneous monolayer of GPTMS cannot be taken as granted on every oxide surface, since it has been shown that multilayers can form and that the molecules can be oriented in various manners to the surface (Kinloch 2006 and ref. therein). For the three kinds of surfaces, we noted homogenous topography of GPTMS films on ITO similar to a surface covered by nanoparticles (Supplementary Figure A2) with higher RMS deviation ( $\geq 1.6 \mathrm{~nm}$ ) compared to non silanized ITO (RMS $<0.4 \mathrm{~nm}$ ). In addition, as shown on the graph (Figure 4), the contact angle showed hydrophobic values for all the treated surfaces $\left(\geq 50^{\circ}\right)$. These results are in agreement with those found by [19,42-47].

The surface topology resemblance between the different treated surfaces may suggest that the GPTMS deposition was not affected with the surface variation. To verify this, surface chemistry was evaluated by XPS to determine the degree of silane surface coverage (Table 1). Our first observation is the high concentration of silicium detected on ITO after GPTMS adsorption. XPS data suggests that the GPTMS molecules attached better at the piranha-treated surface with $14.6 \%$ of total Si compared to bare and $\mathrm{KOH}$-treated (6.9\%). With XPS, the surface composition can be quantified in a range thickness of 20-30 Angstrom depth. Taking into account that the extended length of the epoxysilane molecule (9.5 $)$ [19], we may confirm that with the Piranha treatment we obtain higher covered
ITO surface with superposed GPTMS layers. Altogether, the obtained results, applying a combination of local and global techniques, suggest that the use of piranha treatment is not damaging the surface and may offer stable starting substrate for protein immobilization.

\section{Biofunctionalization by $6 \mathrm{His}$-tagged proteins}

The following step was the grafting of NTA, a chelating molecule, to the epoxy groups on the Piranha-treated ITO/GPTMS surface. The presence of the NTA moieties on the surface was confirmed by the slight increase of the N 1s component in the XPS spectra (Table 2), and by an extra peak in $\mathrm{C} 1 \mathrm{~s}$ at $289.5 \mathrm{eV}$ due to the NTA carboxyl groups (data not shown). As expected, grafting of these carboxyl groups induced a decrease in contact angle $\left(\approx 8^{\circ}\right.$, Figure 4$)$. The final step of this biofunctionalization was the grafting of a hexahistidine-tagged protein, here the two outermost extracellular modules of E-cadherin, E/EC12. These fragments were synthesized as described by Perret et al. [34]. A genetically engineered $6 \mathrm{His}$-tag was added to the C-terminal pair modules to specifically bind with a defined orientation to $\mathrm{Ni}^{2+}$ NTA moieties, consequently forming a $6 \mathrm{His}-\mathrm{Ni}-\mathrm{NTA}$ complex. This chelation cage was stabilized by covalent binding performed using EDC/NHS. Residual non covalently linked E/EC12 proteins were removed with an EDTA/imidazole mixture as described in [25]. XPS data confirmed the grafting of the protein (Table 2). The $\mathrm{N} \mathrm{1s} \mathrm{signal}$ increased about five times after E/EC12 immobilization (0.6 vs. 3.8 and 0.6 vs. 3 at $\%$ for bare and $\mathrm{KOH}$-treated ITO, respectively). However, E/EC12 immobilization on Piranha-treated ITO was three times more important (0.4 vs. 6.0 at\%), which confirmed our previous suggestions about the efficiency of the Piranha treatment (Supplementary Figure A1).

For the purpose of this study, we performed an AFM analysis using the contact mode in liquid (20 mM Hepes, $\mathrm{pH}$ 7.0) with soft $\mathrm{Si}_{3} \mathrm{~N}_{4}$ cantilevers to characterize the oriented grafting of protein fragments on one of these surfaces. We clearly visualized the 10 -nm length cadherin fragments that were free to move around their covalent anchoring bond (Supplementary Figure A2b). To support our statement, we carried out the following experiment: during image acquisition, the applied force was alternately increased then decreased every 20 lines of scan. When the net force exceeded a critical threshold of about $100 \mathrm{pN}$, we observed a flattening of the globular topography shown in Supplementary Figure A2b, from $10 \mathrm{~nm}$ to $3 \mathrm{~nm}$ average heights. The initial globular structure was restored when the force was reduced below $100 \mathrm{pN}$. We also recovered the globular topography in the backward image of the same area. We could thus exclude artifacts due to irreversible scratching of the molecular layer.

\section{Electroactivity}

We investigated the ITO electrochemical response by EIS (Supplementary Figure A3). EIS allows determination of the charge transfer resistance, $R_{\mathrm{ct}}=R T /\left(F i_{0}\right)$, where $i_{0}=F A \mathrm{k}^{0} \mathrm{C}$ is the exchange current, with $F$ the Faraday constant, $T$ the temperature, $A$ the

\begin{tabular}{|c|c|c|c|c|c|}
\hline \multicolumn{2}{|c|}{} & \multicolumn{5}{|c|}{ Element (\%) } \\
\hline Substrate & Treatment & $\mathbf{C}$ & $\mathbf{O}$ & $\mathbf{S i}$ & $\mathbf{N}$ \\
\hline ITO/../NTA & \multirow{2}{*}{ Bare } & 39.5 & 37.8 & 6.6 & 0.6 \\
\hline ITO/../EC12 & & 49 & 31 & 6.8 & 3.8 \\
\hline ITO/../NTA & \multirow{2}{*}{ KOH-treated } & 38 & 37 & 4 & 0.6 \\
\hline ITO/../EC12 & & 40 & 35.5 & 4 & 3 \\
\hline ITO/../NTA & \multirow{2}{*}{ Piranha-treated } & 36.1 & 45.7 & 9 & 0.4 \\
\cline { 1 - 4 } & & 39.4 & 35.7 & 4.5 & 6.0 \\
\hline ITO/../EC12 & \multirow{2}{*}{ *ITO/../NTA: ITO/GPTMS/NTA; ITO/../EC12: ITO/GPTMS/NTA/EC12 } \\
\hline
\end{tabular}

Table 2: XPS surface composition of bare, $\mathrm{KOH}$ and Piranha treated ITO, and after NTA and EC12 molecules grafting (C, O, Si and N atomic \%). 
Citation: Ismail MB, Pastor NC, Soler EP, Soltani A, Othmane A (2016) A Comparative Study on Surface Treatments in the Immobilization Improvement of Hexahistidine-tagged Protein on the Indium Tin Oxide Surface. J Nanomed Nanotechnol 7: 372. doi:10.4172/2157-7439.1000372

Page 5 of 6

electroactive surface area, $k^{0}$ the standard rate constant, and $C$ the bulk concentration of the redox species at equilibrium $[41,42] . R_{\mathrm{ct}}$ is thus inversely proportional to the electroactive surface area $A$ and the standard rate constant $k^{0}$ in the formalism of Butler-Volmer. By covering the electrode with a molecular layer, we expect a decrease of $A$ and $k^{0}$, hence an increase of $R_{\mathrm{ct}}$. The $\mathrm{Fe}(\mathrm{CN})_{6}^{3-/ 4-}$ redox couple was used as an electrochemical probe to monitor the heterogeneous charge transfer efficiency, which is modified depending upon the nature and density of molecules covering the surface [43]. We found $R_{\mathrm{ct}}=165 \Omega . \mathrm{cm}^{2}$ for Piranha-treated ITO. After GPTMS deposition, $R_{\mathrm{ct}}$ reached $2830 \Omega \cdot \mathrm{cm}^{2}$, and the electrochemical response was typical of a strongly blocked electrode [42]. The low frequency response showed that the electrochemical reaction was irreversible and not limited by mass transport. This suggests that the GPTMS layer covered the whole surface and that redox species diffusion occurred through microscopic pores, pinholes or cracks. Our result agrees with previous works showing that GPTMS coating prevents diffusion and charge transfer of the redox probe to the electrode surface $[22,44]$. At the end of the biofunctionalization treatment, we observed a decrease in Rct $(280$ $\Omega . \mathrm{cm}^{2}$ ) and a behavior consistent with diffusion-limited process, probably due to the oxido-reduction process at the electrode interface involving amino acids and functional groups present in the proteins' side chains [45-47].

\section{Conclusion}

We have presented a comparative study of surface treatments with focus on surface state. The study involved three chemical treatments that affected the final hexahistidine tag protein yields on the top of the ITO. The surface obtained was presented an oriented grafting of globular proteins via NTA-terminated GPTMS molecules. Such an immobilization strategy of recombinant proteins integrated in a microfluidic system equipped for electrochemical detection could provide versatile surfaces of high quality for electrochemical detection of soluble compounds, as well as cells.

\section{Acknowledgements}

This work is the fruitful effort of different collaborations. A special thanks to $\mathrm{Dr}$. Hélène Feracci and Dr. Jean-Paul Salvetat for their important contributions. The work was supported by institutional funding from CNRS (France), a CNanoGSO grant (Hélène Feracci, Jean-Paul Salvetat), and by the Ministry of Higher Education and Research of Tunisia. The ICMAB experiments were financed by Science Ministry Grant (MAT2011-24363) and Marato TV3 Foundation Grant (reference 110130/31) (Dr. Nieves Casan). MBI stay at the CRPP and ICMAB was funded by a Ministry of Higher Education and Research of Tunisia fellowship. We are grateful to Sébastien Chevalier for his help in early experiments, to Elizabeth Hillard for editing checking the manuscript, to Marwa Sahraoui, Andres Gomez, and Christine Labrugère.

\section{References}

1. Gao J, Chen R, Li DH, Jiang L, Ye JC, et al. (2011) UV light emitting transparent conducting tin-doped indium oxide (ITO) nanowires. Nanotechnology 22 : 195706.

2. Kim H, Pique A, Horwitz JS, Mattoussi H, Murata $H$, et al. (1999) Indium tin oxide thin films for organic light-emitting devices. Applied Physics Letters 74 : 3444-3446.

3. Liu G, Kerr JB, Johnson S (2004) Dark spot formation relative to ITO surface roughness for polyfluorene devices. Synthetic Metals 144: 1-6.

4. You ZZ (2007) Combined AFM, XPS, and contact angle studies on treated indium-tin-oxide films for organic light-emitting devices. Materials Letters 61: 3809-3814.

5. Ngamsinlapasathian S, Sreethawong T, Suzuki Y, Yoshikawa S (2006) Doubled layered ITO/SnO2 conducting glass for substrate of dye-sensitized solar cells. Solar Energy Materials and Solar Cells 90: 2129-2140.

6. Zhou Y, Li F, Barrau S, Tian W, Inganäs O, et al. (2009) Inverted and transparent polymer solar cells prepared with vacuum-free processing. Solar Energy Materials and Solar Cells 93: 497-500.
7. Gardonio S, Gregoratti L, Scaini D, Castellarin-Cudia C, Dudin P, et al. (2008) Characterization of indium tin oxide surfaces after $\mathrm{KOH}$ and $\mathrm{HCl}$ treatments. Organic Electronics 9: 253-261.

8. Kim JS, Granstrom M, Friend RH, Johansson N, Salaneck WR, et al. (1998) Indium-tin oxide treatments for single- and double-layer polymeric light-emitting diodes: The relation between the anode physical, chemical, and morphological properties and the device performance. Journal of Applied Physics 84: 6859-6870.

9. Purvis KL, Lu G, Schwartz J, Bernasek SL (2000) Surface characterization and modification of indium tin oxide in ultrahigh vacuum. Journal of the American Chemical Society 122: 1808-1809.

10. Dong H, Zhang X, Niu Z, Zhao D, Li J, et al. (2013) Indium tin oxide nanowires grown by one-step thermal evaporation-deposition process at low temperature. J Nanosci Nanotechnol 13: 1300-1303.

11. George J, Menon CS (2000) Electrical and optical properties of electron beam evaporated ITO thin films. Surface and Coatings Technology 132: 45-48.

12. Khusayfan NM, El-Nahass MM (2013) Study of Structure and Electro-Optical Characteristics of Indium Tin Oxide Thin Films. Advances in Condensed Matter Physics.

13. Mergel D, Thiele K, Qiao ZH (2005) Texture analysis of thin In2O3: Sn films prepared by direct-current and radio-frequency magnetron-sputtering. Journal of Materials Research 20: 2503-2509.

14. Ruan C, Yang L, Li Y (2002) Immunobiosensor chips for detection of Escherichia coil O157:H7 using electrochemical impedance spectroscopy. Anal Chem 74 4814-4820.

15. Simsek CS, Teke M, Sezginturk MK (2014) An ITO Based Disposable Biosensor for Ultrasensitive Analysis of Retinol Binding Protein. Electroanalysis 26: 328-339.

16. Zanina N, Haddad S, Othmane A, Jouenne T, Vaudry D, et al. (2012 Endothelial cell adhesion on polyelectrolyte multilayer films functionalised with fibronectin and collagen. Chemical Papers 66: 532-542.

17. Fukushi Y, Kominami H, Nakanishi Y, Hatanaka Y (2005) Effect of ITO surface state to the aging characteristics of thin film OLED. Applied Surface Science 244: 537-540.

18. Lu D, Wu Y, Guo JH, Lu G, Wang Y, et al. (2003) Surface treatment of indium tin oxide by oxygen-plasma for organic light-emitting diodes. Materials Science and Engineering B-Solid State Materials for Advanced Technology 97: 141-144.

19. Luzinov I, Julthongpiput D, Liebmann-Vinson A, Cregger T, Foster MD, Tsukruk VV (2000) Epoxy-terminated self-assembled monolayers: Molecular glues for polymer layers. Langmuir 16: 504-516.

20. Kang CK, Lee YS (2012) Carbohydrate polymer grafting on stainless stee surface and its biocompatibility study. Journal of Industrial and Engineering Chemistry 18: 1670-1675.

21. Mrad M, Montemor MF, Dhouibi L, Triki E (2012) Deposition of hybrid 3-GPTMS's film on AA2024-T3: Dependence of film morphology and protectiveness performance on coating conditions. Progress in Organic Coatings 73: 264-271.

22. Hao C, Yan F, Ding L, Xue Y, Ju H (2007) A self-assembled monolayer based electrochemical immunosensor for detection of leukemia K562A cells. Electrochemistry Communications 9: 1359-1364.

23. Shindo H, Kuwamori M, Taniguchi M (2012) Adhesion of tissue sections from eleven organs on glass slides with amino group coatings. Journal of Bioscience and Bioengineering 113: 661-664.

24. Zengin A Caykara T (2011) Immobilization of immunoglobulin $G$ in a highly oriented manner on a protein-A terminated multilayer system. Applied Surface Science 257: 2111-2117.

25. Chevalier S, Cuestas-Ayllon C, Grazu V, Luna M, Feracci H, et al. (2010) Creating biomimetic surfaces through covalent and oriented binding of proteins. Langmuir 26: 14707-14715.

26. Souiri M, Blel N, Sboui D, Mhamdi L, Epalle T, et al. (2014) AFM, CLSM and EIS characterization of the immobilization of antibodies on indium-tin oxide electrode and their capture of Legionella pneumophila. Talanta 118: 224-230.

27. Yang Z, Zong C, Ju H, Yan F (2011) Streptavidin-functionalized capillary immune microreactor for highly efficient chemiluminescent immunoassay. Analytica Chimica Acta 706: 143-148. 
Citation: Ismail MB, Pastor NC, Soler EP, Soltani A, Othmane A (2016) A Comparative Study on Surface Treatments in the Immobilization Improvement of Hexahistidine-tagged Protein on the Indium Tin Oxide Surface. J Nanomed Nanotechnol 7: 372. doi:10.4172/2157-7439.1000372

Page 6 of 6

28. Lamture JB, Beattie KL, Burke BE, Eggers MD, Ehrlich DJ, et al. (1994) Direct detection of nucleic acid hybridization on the surface of a charge coupled device. Nucleic Acids Res 22: 2121-2125.

29. Grazu V, de la Fuente JM, Feracci H (2010) Spain Patent No. P200931092.

30. Takeichi M1 (1995) Morphogenetic roles of classic cadherins. Curr Opin Cell Biol 7: 619-627.

31. Berx G, van Roy F (2009) Involvement of members of the cadherin superfamily in cancer. Cold Spring Harb Perspect Biol 1: a003129.

32. Patel SD, Chen CP, Bahna F, Honig B, Shapiro L (2003) Cadherin-mediated cellcell adhesion: sticking together as a family. Curr Opin Struct Biol 13: 690-698.

33. Perret E, Benoliel AM, Nassoy P, Pierres A, Delmas V, et al. (2002) Fast dissociation kinetics between individual E-cadherin fragments revealed by flow chamber analysis. Embo Journal 21: 2537-2546.

34. Perret E, Leung A, Feracci H, Evans E (2004) Trans-bonded pairs of E-cadherin exhibit a remarkable hierarchy of mechanical strengths. Proceedings of the National Academy of Sciences of the United States of America 101: 16472-16477.

35. Arulanandam R, Vultur A, Cao J, Carefoot E, Elliott BE, et al. (2009) CadherinCadherin Engagement Promotes Cell Survival via Rac1/Cdc42 and Signal Transducer and Activator of Transcription-3. Molecular Cancer Research 7: $1310-1327$.

36. Raptis L, Arulanandam R, Vultur A, Geletu M, Chevalier S, et al. (2009) Beyond structure, to survival: activation of Stat by cadherin engagement. Biochemistry and Cell Biology-Biochimie Et Biologie Cellulaire 87: 835-843.

37. Wilson R, Schiffrin DJ (1995) use of fluorescamine for the spectrofluorometric investigation of primary amines on silanized glass and indium tin oxide-coated glass. Analyst 120: 175-178.

38. Armstrong NR, Carter C, Donley C, Simmonds A, Lee P, et al. (2003) Interface modification of ITO thin films: organic photovoltaic cells. Thin Solid Films 445: 342-352.
39. Bazin D, Chevalier S, Saadaoui H, Santarelli X, Larpent C, et al. (2012) Electrodeposition of Polymer Nanodots with Controlled Density and Their Reversible Functionalization by Polyhistidine-Tag Proteins. Langmuir 28: 13968-13975.

40. D'Elia S, Scaramuzza N, Ciuchi F, Versace C, Strangi G, Bartolino R (2009) Ellipsometry investigation of the effects of annealing temperature on the optical properties of indium tin oxide thin films studied by Drude-Lorentz model. Applied Surface Science 255: 7203-7211.

41. Liau YH, Scherer NF (2001) Nanoscale Electrical Conductivity and Surface Spectroscopic Studies of Indium-Tin Oxide. J Phys Chem B 105: 3282-3288.

42. Bard AJ, Faulkner LR (2001) Electrochemical methods: fundamentals and applications ( $2^{\text {nd }}$ edtn.), New York: Wiley.

43. Fu YZ, Yuan R, Tang DP, Chai YQ, Xu L (2005) Study on the immobilization of anti-lgG on Au-colloid modified gold electrode via potentiometric immunosensor, cyclic voltammetry, and electrochemical impedance techniques. Colloids and Surfaces B-Biointerfaces 40: 61-66.

44. Wei MY, Wen SD, Yang XQ, Guo LH (2009) Development of redox-labeled electrochemical immunoassay for polycyclic aromatic hydrocarbons with controlled surface modification and catalytic voltammetric detection. Biosensors and Bioelectronics 24: 2909-2914.

45. Smiechowski MF, Lvovich VF, Roy S, Fleischman A, Fissell WH, et al (2006) Electrochemical detection and characterization of proteins. Biosens Bioelectron 22: 670-677.

46. Briggs D (1998) Surface analysis of polymers by XPS and static SIMS Cambridge etc.: Cambridge University Press.

47. Satyanarayana N, Sinha SK, Lim SC (2009) Highly wear resistant chemisorbed polar ultra-high-molecular-weight polyethylene thin film on Si surface for microsystem applications. Journal of Materials Research 24: 3331-3337. 